\title{
Study on Teaching Concept and Curriculum Design of Flipped Classroom
}

\author{
Xi Sun \\ Department of Humanistic Management, Jiangxi Police Institute, Jiangxi, China, 330103
}

Keywords: Teaching Concept, Curriculum Design, Flipped Classroom

\begin{abstract}
At present, the overturning of classroom teaching has gradually become familiar to everybody. The emergence of this teaching method has accelerated the speed of education informatization at home and abroad. At the same time, due to the advantages of this teaching method, some classrooms and schools in China and abroad have adopted this teaching method for teaching activities of the design. Under the guidance of the teaching philosophy of turning over the classroom, how to make the teaching activities turn over in the true sense of teaching, how to design the teaching content of the course and how to support the curriculum have become the main problems that everybody pays attention to now.
\end{abstract}

\section{Introduction}

The traditional teaching model is the teacher in the classroom lectures, homework assignments, so that students go home practice. Different from the traditional classroom teaching mode, under the overturning classroom teaching mode, students complete the learning of knowledge after class, and the classroom becomes a place for interaction between teachers and students and students, including Q \& A, knowledge Use, etc., so as to achieve better educational effect. The popularization of the Internet and the application of computer technology in the field of education make it possible to turn the classroom teaching model into reality and reality. Students can use high-quality educational resources via the Internet and no longer rely on lecturers to teach knowledge. The role of classroom and teacher has changed. Teachers are more responsible for understanding students' problems and for guiding students to apply knowledge.

\section{The Theoretical Basis of Flip Classroom Design}

Blended learning is a new term in the field of education, which is considered as a combination of online learning and face-to-face learning. Professor Li Ke-dong believes that "blended learning is a term that appears in the field of education, especially in the field of education and technology after its reflection on online learning. Its main idea is to integrate the two learning modes of face-to-face teaching and online learning so as to achieve Reduce costs and improve efficiency of a teaching method. "Professor He Kekang pointed out that" the so-called Blended Learning is to combine the advantages of traditional learning methods and e-Learning; that is, it is necessary to play a teacher guide, inspire, monitor teaching The leading role of the process, but also reflect the students as the main body of the learning process initiative, enthusiasm and creativity. "Digital learning is based on digital learning As the core of information technology and curriculum integration, different from the traditional learning methods, has the following distinctive features: (1) learning is student-centered, learning is personalized, to meet the individual needs; (2) learning is based on the problem or theme As the center; (3) learning process is carried out through Exchanges between learners are negotiated, cooperative; (4) learning is a creative and regenerative properties; (5) lifelong learning is anytime, anywhere. This course uses three online teaching platforms: online course platform, teacher blog and classroom teaching. Combine online learning with face-to-face teaching, provide abundant teaching resources, online communication, online testing and teaching evaluation system on the platform, give full play to the role of teacher-led and student body, and promote the initiative of students in order to improve the teaching effect the goal of. 
Flip classroom learning environment is to allow students to use a wealth of online teaching resources and collaborative learning platform before class, under the guidance of the teacher, according to certain topics, read the relevant resources, try to understand the knowledge, after the students learn in the actual classroom, students conduct learning test and ask questions, teachers and students to analyze and discuss the topic content. Students and students can deepen their understanding of these knowledge and internalize knowledge through the discussion of teachers and students in the classroom so that under the guidance of teachers, students can help them to form learning emotions, attitudes and values and help students to master complex and systematic subjects know how. The following table is a comparison of the various elements of the traditional classroom and flip classroom:

The teacher in traditional teaching plays the role of imparting knowledge and is the protagonist in teaching. Students passively pass on the knowledge. The imparting process of knowledge is carried out by teachers in the classroom. The internalization of knowledge, that is, In the flip class, the teacher as the teaching activity guide, the student is the protagonist in teaching, is the active researcher of knowledge, the impartment of knowledge is completed before class, the internalization of knowledge is in the classroom by teachers and students together to complete the evaluation method using a variety of ways. These contents provide some guidance for the design of this course, and also provide a practical reference for the course design.

\section{The Design and Development of Flip Classroom Teaching Network Curriculum}

According to the relevant theoretical foundation of online teaching resources, the contents of videos, animations, pictures and so on used in the course should be compressed in file size under the premise of maintaining the quality, so that the file capacity is relatively small, which is convenient for online viewing and downloading. Our course videos in course development mainly use Flv streaming media format, teachers and students can watch the video directly through the network platform without having to download to the local computer. At the same time, to ensure the integrity of the premise, the video as small as possible, easy to save and download, reduce the students in the process of watching annoying emotions. In the course of resource development, we can make use of the Flash video format teaching video as much as possible to use the animation format. The animation in the course is mainly teaching animation in skill teaching. Compared with the video media, the animation file is smaller and easier to download and save . In addition, a level of navigation throughout the site runs through the course, providing the jump between the rest of the modules. In addition to the home page, each level of navigation arranged in a fixed position of sub-module pages to facilitate students to find the appropriate learning module or learning resources to reduce navigation jumps should be required to find the time-consuming and avoid students need to find the navigation jump process Negative learning emotions, thereby enhancing learning efficiency. Similarly, in the design of the sub-module of the second-level navigation, the second-level navigation links unified fixed on the left side of the page. In addition, at the top of each sub-module page's learning content, it lists the corresponding path of the sub-module page, indicating the location of the sub-module where the content is located so that students can quickly grasp the location of the learning content.

\section{The Evaluation Flip Classroom Teaching}

Through the action research and the statistical analysis of the questionnaire, the author summarizes the application of flip classroom teaching in universities: (1) Flip classroom teaching methods to promote learning science and technology courses in addition to the above results can be proved Through the interviews with teachers, I learned that, compared with the previous teaching classes of teachers, teaching activities using flip classroom teaching can more effectively improve students' learning motivation and make learning more Knowledge and skills, can well regulate the atmosphere of classroom learning, inspire teachers 'enthusiasm for teaching and students' enthusiasm for learning. 
(2) Flip classroom teaching method can be applied to the teaching of university teaching as a case of college teaching, with action cases proved that the teaching of college classrooms can be used to flip the way. This study has achieved good teaching results. My tutor is prepared to continue using the overturning classroom teaching method in our information technology course. (3) Turn the classroom teaching method can be gradual approach to teaching in colleges and universities As the turnover of classroom teaching students contact is not much, at the same time, this teaching method and students in the past the traditional way of learning is not the same, students need to learn Therefore, teachers can adopt a gradual way to refer to this teaching method in the course so that students gradually adapt to this teaching method in order to ensure the orderly development of teaching activities.

(4) Pre-class learning activities should be carried out with assurance As a result of the teaching method of overturning classrooms, students must complete the contents of pre-class learning activities on time and in good quality, and only the majority of students complete this part Of the learning activities, the classroom teaching activities can be successfully carried out, even if only a few students did not finish the pre-class learning activities on time, in the classroom activities will have an impact on the progress of the entire course. Therefore, pre-class learning activities must be rigorous monitoring of learning progress, in order to supervise the students to learn before class.

(5) classroom learning activities should be subject to discussion or task-based classroom learning activities arrangements, as students have conducted before the class explicit knowledge of learning, in the classroom, teachers should arrange classroom discussions or classroom tasks based practice , Supplemented by proper explanation, so as to ensure that teachers and students face to face discussion or students in hands-on practice, found that problems can communicate with teachers or other students in time, teachers can find more students in practical learning problems encountered, At the same time, teachers and students to provide more counseling and exchange opportunities.

(6) Classroom learning activities To have a clear goal Each class in the learning activities, teachers should give a clear learning tasks, students only under clear learning tasks, can be purposeful personal learning and group learning in order to obtain Planned teaching effectiveness.

\section{Conclusion}

As a teaching mode, the flip classroom can be implemented by a variety of teaching methods in teaching practice. The successful teaching methods include peer teaching, problem-based learning and case teaching. Flip classroom teaching mode is the easiest part of the task of teaching that knowledge transfer to the classroom outside the classroom for students to learn independently and make full use of classroom teachers and students, students and students face to face opportunities for positive socialization Interaction, to achieve in-depth learning, training students to solve problems, creative thinking, high level of reasoning and critical thinking skills such as education goals. Student center, autonomous learning and cooperative learning have important meaning in overturning classroom teaching mode, which is the basis of their construction. According to flip the classroom teaching model depends on whether the information technology - watch the video as an element, flip the classroom can be divided into first-generation flip classroom and second-generation flip classroom. Watching the video itself does not bring good learning results, flip the classroom does not necessarily operate in the information environment, and information technology for flip classroom to provide more rich teaching resources and more interactive forms. In teaching practice to flip classroom teaching mode to obtain good teaching effect, we must attach importance to education philosophy, curriculum design, student participation, curriculum evaluation and information technology five key elements.

\section{References}

[1] Jinling Salman Khan how to move to "flip the classroom" [J]. China Information Technology Education, 2012, (10): 29. 
[2] Zheng Xiao-Jun, YANG Man-Fu.Research and Practice of Network Learning Ability Cultivation of High Normal School Students in Local Normal Universities - Taking Guangxi Normal University as an Example [J]. China Education News, 2012, (23): 51-53.

[3] Zhang Yujiang. Flip classroom change [J]. China Information Technology Education, 2012, (10): 118-121.

[4] Zou Jingping. Flip classroom origins and success [J]. China distance education, 2012, (14) 